\title{
Serial interspike interval correlations of excitable neurons with memory
}

\author{
Tilo Schwalger* and Benjamin Lindner
}

\author{
Address: Max-Planck-Institut für Physik komplexer Systeme, 01187 Dresden, Germany \\ Email: Tilo Schwalger* - tilo@pks.mpg.de \\ * Corresponding author
}

from Eighteenth Annual Computational Neuroscience Meeting: CNS*2009

Berlin, Germany. 18-23 July 2009

Published: 13 July 2009

BMC Neuroscience 2009, 10(SuppI I):PI22 doi:I0.II86/I47|-2202-I0-SI-PI22

This abstract is available from: http://www.biomedcentral.com/I47I-2202/I0/SI/PI22

(c) 2009 Schwalger and Lindner; licensee BioMed Central Ltd.

Many theoretical studies of spiking neurons rely on the simplifying renewal assumption, meaning that interspike intervals (ISIs) of a spike train are statistically independent. Experimental measurements of serial ISI correlations have revealed, however, that the renewal assumption is violated in various systems. For instance, strong but shortlived, negative correlations have been reported for P-units of weakly electric fish $[1,2]$ and for pyramidal neurons in rat entorhinal cortex [3]. For a review, see [4]. Positive correlations that extend over many ISIs have been observed in [5]. Neurons exhibiting spike-frequency adaptation typically display negative serial correlations, whereas slow input variations typically induce positive serial correlations [6].

Theoretical work has gained much insight into the beneficial role of serial correlations for signal transmission [7]. In that case, the calculation of the serial correlation coefficient (SCC) could be accomplished by the use of a particularly simple neuron model that operates in the oscillatory regime and features a dynamic firing threshold. In general, however, the SCC is difficult to access analytically, which is due to the non-Markovian nature of nonrenewal neuron models. Here, we present a novel technique that allows us to calculate the SCC of a large class of non-renewal neurons operating in the excitable regime. Specifically, we consider neurons with discrete internal states or discrete states of the external driving function. The analytical approach is based on a generalization of the discrete kinetic scheme used to investigate residence time correlations in driven bistable systems $[8,9]$.

Having established the general method to obtain the SCC for arbitrary lags between ISIs, we consider two special cases that are of particular interest. The first case mimics a leaky integrate-and-fire (LIF) neuron with dynamic threshold, which has been proposed as a model for spikefrequency adaptation. By discretizing the threshold into three states, we find a negative SCC at lag one and vanishing correlations at higher lags. In the second case, we consider a neuron that participates in a network that switches between Up and Down states. The theory reveals positive serial correlations that decay exponentially with the lag. Interestingly, for slow two-state synaptic input the SCC at lag one is maximized at an optimal amplitude of the twostate driving. Our theoretical expressions agree well with extensive simulations of noisy LIF neurons. Finally we mention, that an analytical formula for the SCC could be useful to model measured data by tuning the parameters of the discrete neuron model.

\section{References}

I. Ratnam R, Nelson ME: Nonrenewal statistics of electrosensory afferent spike trains: implications for the detection of weak sensory signals. J Neurosci 2000, 20:6672.

2. Chacron MJ, Longtin A, St-Hilaire M, Maler L: Suprathreshold stochastic firing dynamics with memory in P-type electroreceptors. Phys Rev Lett 2000, 85:1576.

3. Engel T, Schimansky-Geier L, Herz A, Schreiber S, Erchova I: Subthreshold membrane-potential resonances shape spike-train patterns in the entorhinal cortex. J Neurophysiol 2008, 100:1576-1589. 
4. Farkhooi F, Strube-Bloss MF, Nawrot MP: Serial correlation in neural spike trains: Experimental evidence, stochastic modeling, and single neuron variability. Phys RevE 2009, 79:02 I 905.

5. Lowen SB, Teich MC: Auditory-nerve action potentials form a nonrenewal point process over short as well as long time scales. J Acoust Soc Am 1992, 92:803.

6. Schwalger T, Schimansky-Geier L: Interspike interval statistics of a leaky integrate-and-fire neuron driven by Gaussian noise with large correlation times. Phys Rev E 2008, 77:031914.

7. Chacron MJ, Lindner B, Longtin A: Noise shaping by interval correlations increases information transfer. Phys Rev Lett 2004, 92:08060I.

8. Lindner $B$, Schwalger $T$ : Correlations in the sequence of residence times. Phys Rev Lett 2007:210603.

9. Schwalger T, Lindner B: Higher-order statistics of a bistable system driven by dichotomous colored noise. Phys Rev $E$ 2008:02I|2I.

Publish with Bio Med Central and every scientist can read your work free of charge

"BioMed Central will be the most significant development for disseminating the results of biomedical research in our lifetime. "

Sir Paul Nurse, Cancer Research UK

Your research papers will be:

- available free of charge to the entire biomedical community

- peer reviewed and published immediately upon acceptance

- cited in PubMed and archived on PubMed Central

- yours - you keep the copyright 